AperTO - Archivio Istituzionale Open Access dell'Università di Torino

\title{
Photocatalytic hydrogen production on Pt-loaded TiO2 inverse opals
}

\section{This is the author's manuscript}

Original Citation:

Availability:

This version is available http://hdl.handle.net/2318/154640

since 2019-02-04T12:38:59Z

Published version:

DOI:10.1016/j.apcatb.2014.08.028

Terms of use:

Open Access

Anyone can freely access the full text of works made available as "Open Access". Works made available under a Creative Commons license can be used according to the terms and conditions of said license. Use of all other works requires consent of the right holder (author or publisher) if not exempted from copyright protection by the applicable law. 


\section{(3) \\ UNIVERSITÀ DEGLI STUDI DI TORINO}

This Accepted Author Manuscript (AAM) is copyrighted and published by Elsevier. It is posted here by agreement between Elsevier and the University of Turin. Changes resulting from the publishing process - such as editing, corrections, structural formatting, and other quality control mechanisms - may not be reflected in this version of the text. The definitive version of the text was subsequently published in APPLIED CATALYSIS. B, ENVIRONMENTAL, 163 (2015), 452-458, DOI: 10.1016/j.apcatb.2014.08.028.

You may download, copy and otherwise use the AAM for non-commercial purposes provided that your license is limited by the following restrictions:

(1) You may use this AAM for non-commercial purposes only under the terms of the CC-BY-NC-ND license.

(2) The integrity of the work and identification of the author, copyright owner, and publisher must be preserved in any copy.

(3) You must attribute this AAM in the following format: Creative Commons BY-NC-ND license (http://creativecommons.org/licenses/by-nc-nd/4.0/deed.en), http://www.sciencedirect.com/science/article/pii/S0926337314005062 
(revised manuscript)

Photocatalytic hydrogen production on Pt-loaded $\mathrm{TiO}_{2}$ inverse opals

Fabrizio Sordello, Claudio Minero

Dipartimento di Chimica, Università di Torino,Via P: Giuria, 5, 10125 Torino, Italy.

Corresponding authors:

e-mail: fabrizio.sordello@unito.it, claudio.minero@unito.it;

Fax: +39 011670 5242; Tel: +390116705294 / 8449 


\section{Abstract}

$\mathrm{TiO}_{2}$ inverse opals present increased photocatalytic production of $\mathrm{H}_{2} \cdot \mathrm{TiO}_{2}$ inverse opals with different pore size and $\mathrm{TiO}_{2}$ macroporous structures with disordered arrangement of the pores have been tested in the photocatalytic production of hydrogen in aqueous solution with a formate buffer as hole scavenger. $\mathrm{TiO}_{2}$ inverse opals belong to the family of metamaterials and exhibit unique catalytic properties arising from their peculiar interaction with light. To discriminate the effects of slow photons the hydrogen photoproduction, experiments were carried out at two different wavelengths, at $365 \mathrm{~nm}$ where the effect of slow photons is maximized, and at $254 \mathrm{~nm}$ where it is negligible. The resulting hydrogen production rates suggest a strong effect of the slow light and of the polymer template used in the synthesis of the $\mathrm{TiO}_{2}$ powders. The chemical properties of the polymeric sacrificial template determine the crystalline phase of the sample and as a consequence affect the catalytic performances of the resulting $\mathrm{TiO}_{2}$ structures.

Keywords: $\mathrm{TiO}_{2}$, inverse opal, hydrogen production, slow light, slow photons

Abbreviations: PBG: Photonic Band Gap; TIO: $\mathrm{TiO}_{2}$ Inverse Opal; MP: macroporous; XRD: X-Ray Diffraction; PMMA: Polymethylmethacrylate; PS: Polystyrene 


\section{Introduction}

Photonic crystals are materials in which the refractive index varies periodically in the space, and, since light can be refracted and reflected at each interface, for a wavelength matching the lattice periodicity there is the possibility to have constructive interference of the reflected waves. At that wavelength light is completely reflected and cannot propagate inside the material because of the presence of the photonic band gap (PBG) $[1,2]$. Owing to this, photonic crystals find applications as dielectric mirrors [3-6], waveguides [7], lasing cavities [8, 9], black body radiation modifiers [10]. At the PBG edges light can propagate inside the photonic crystal, but its group velocity is strongly reduced, and thus its interaction with the material increases, opening the field to a series of diversified applications $[11,12]$.

The increased light-matter interaction can be exploited in photocatalysis. Recently Tsai et al. published an interesting report [13] on the interaction of light with hierarchical structured $\mathrm{TiO}_{2}$, specifically hollow spheres, which could harvest more light thanks to the scattering effect in the microstructure while maintaining high surface area. Among photonic crystals $\mathrm{TiO}_{2}$ inverse opals (TIOs) have been studied extensively to improve the efficiency of the photocatalytic process [1416]. TIOs are constituted of ordered arrays of holes in $\mathrm{TiO}_{2}$ matrix, but they only possess a partial PBG, because the refractive index of $\mathrm{TiO}_{2}$ is not high enough to open an omnidirectional gap [17]. Previous results show that TIOs can significantly increment the photocatalytic performances of $\mathrm{TiO}_{2}$ thanks to the slow light phenomenon, which is the improved light-matter interaction due to the reduction of the group velocity of light at the PBG edges [18-21]. In a previous work [21] we have clarified that besides slow photons, porosity and specific surface area give only a negligible contribute to the observed increase in photocatalytic activity of these structures. The photoelectrochemical study of such materials [22] showed that TIOs and disordered macroporous $\mathrm{TiO}_{2}$ structures share the same recombination rate of the photogenerated charge carriers, but TIOs are characterized by a faster electron transfer to the oxygen present in solution. After our early analysis, other research works observed that the slow photons effect markedly improved the 
photocatalytic activity in the oxidation of dyes [23], and increased three times the performance of $\mathrm{Bi}_{2} \mathrm{WO}_{6}$ deposited on $\mathrm{SiO}_{2}$ photonic crystal compared to ordinary $\mathrm{Bi}_{2} \mathrm{WO}_{6}$ films [24]. The slow photon effect was also responsible for the enhanced photodegradation of the AO7 dye on TIOs doped with $\mathrm{Ti}^{3+}$ [25]. Conversely, the porous structure plays an important role in electrocatalytic reactions [26]. Thus the enhanced absorption of light, the improved reactivity towards oxygen and, to a lesser extent, the improved mass transfer of substrates make TIOs good candidates as catalysts for photo-reduction reactions.

To test the presence of a synergic effect between slow light and faster electron transfer to solution, in the present work we have compared the activity of Pt-loaded TIOs and of Pt-loaded macroporous disordered $\mathrm{TiO}_{2}$ structures in hydrogen photoproduction experiments. To detect the effect of slow photons we performed irradiations at two different wavelengths: at $365 \mathrm{~nm}$, where the TIOs synthesized can take advantage of slow light, and at $254 \mathrm{~nm}$, where for the TIOs considered the slow light contribution to the photocatalytic activity is negligible. The hydrogen production rates of TIO samples are then compared with those of disordered macroporous samples.

\section{Experimental}

\subsection{General}

$\mathrm{TiO}_{2}$ P25 was a gift of Degussa, methyl methacrylate (MMA, 99\%), styrene (99\%), 2,2'-azobis(2methylpropionamidine) dihydrochloride (97\%), titanium (IV) isopropoxide (97\%), hexachloroplatinic acid hexahydrate (37.5\% Pt basis), formic acid (85\% in water), ethanol (99.9\%) and ethylene dimethacrylate (98\%), were purchased from Aldrich, sodium formate (99\%) from Merck. All the products were used without further purification.

\subsection{Powders preparation}

TIOs and $\mathrm{TiO}_{2}$ macroporous structures were synthetized using different polymeric sacrificial templates. Polymethylmethacrylate (PMMA) and polystyrene (PS) templates were used to obtain 
$\mathrm{TiO}_{2}$ structures with different pore sizes. The detailed synthesis procedure has been described elsewhere [21], here we only summarize the relevant issues. PMMA syntheses were carried out following a modified method proposed by Waterhouse and Waterland [27], in which the stirring procedure was changed [21]. With vigorous mechanical stirring well monodisperse colloids were produced, whereas with magnetic stirring polydisperse colloids were obtained.

Monodisperse polystyrene (PS) spheres were prepared with emulsion polymerization without emulsifier with a modified version of the method proposed by Goodwin et al.[28]. The size of the PS spheres produced is highly dependent on the composition of the synthesis mixture and on the reaction temperature, while the monodispersity of nanoparticles strongly depends on the stirring of the reaction mixture. To obtain well monodisperse colloids we carried out syntheses with mechanical stirring. Polystyrene polydisperse colloids were obtained mixing various batches of monodisperse colloids.

Polymer colloids size and their polydispersity were measured with an ALV-NIBS High Performance Particle Sizer (ALV GmbH). Polymeric colloidal suspensions were diluted approximately from 5 to 100-fold with Milli Q water before measurements and the particle size was extrapolated at infinite dilution.

Opals made with monodisperse polymer particles and polymeric disordered structures have been prepared loading PMMA or PS colloidal suspensions into $50 \mathrm{~mL}$ plastic falcon tubes followed by centrifugation $\left(4300 \mathrm{rpm}, 15^{\circ} \mathrm{C}\right.$ for $\left.90 \mathrm{~min}\right)$. The supernatant was then removed, and the polymeric disordered structure or the polymeric colloidal crystal was left to dry in air at $25^{\circ} \mathrm{C}$ for 24 hours.

Macroporous $\mathrm{TiO}_{2}$ (MP) and TIOs were prepared filling the interstices among polymer spheres in polymeric disordered structures and polymeric opals with a $\mathrm{TiO}_{2}$ precursor. $1.5 \mathrm{~g}$ of the polymer template were gently crushed with a metal spatula to give fractured pieces of size $<2 \mathrm{~mm}$, which

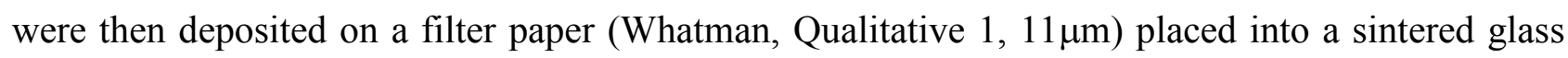
filter funnel (Millipore). With a strong vacuum applied to the sintered glass filter funnel, a solution of $\mathrm{TiO}_{2}$ precursor (4 $\mathrm{mL}$ titanium (IV) isopropoxide and $4 \mathrm{~mL}$ ethanol) was poured drop wise over 
the surface of the polymeric structure. Infiltrated samples were then left to dry in air at $25^{\circ} \mathrm{C}$ for $2 \mathrm{~h}$ and recovered. Polymeric templates were then removed by means of calcination in air using the following protocol: the temperature was raised from 25 to $300^{\circ} \mathrm{C}$ at $2{ }^{\circ} \mathrm{C} \min ^{-1}$, held at $300^{\circ} \mathrm{C}$ for 5 $\mathrm{h}$, then raised again from 300 to $550^{\circ} \mathrm{C}$ at $2^{\circ} \mathrm{C} \min ^{-1}$, held at $550^{\circ} \mathrm{C}$ for $12 \mathrm{~h}$. Samples were then finally allowed to cool to room temperature over 3-4 h.

On the as prepared materials, $\mathrm{Pt}$ was photocatalytically reduced adding $\mathrm{H}_{2} \mathrm{PtCl}_{6}$ to catalyst slurries and irradiating with UV light (see below).

\subsection{X-ray powder diffraction}

X-ray powder diffraction (XRD) patterns have been recorded with a PW3050/60 X'Pert PRO MPD diffractometer from PANalytical working in Bragg-Brentano configuration. The X-ray source was a high power ceramic tube PW3373/10 LFF with a $\mathrm{Cu}$ anode and the instrument was equipped with a Ni filter to attenuate $K_{\beta}$. Diffracted photons were collected with a real time multiple strip X'celerator detector. Powder samples have been hosted on $\mathrm{SiO}_{2}$ amorphous sample holder.

The relative amounts of the different $\mathrm{TiO}_{2}$ polymorphs were assessed with the method proposed by Zhang and Banfield [29].

\subsection{Specific surface area}

The specific surface area (SSA) of the powders synthesized was measured with nitrogen adsorption using an ASAP 2010 instrument (Micromeritics Instrument Corporation). Before the analysis all the samples were outgassed at $300^{\circ} \mathrm{C}$ in vacuum for $24 \mathrm{~h}$. Specific surface area was calculated with the B.E.T. method [30], assuming an area of $0,162 \mathrm{~nm}^{2}$ for the $\mathrm{N}_{2}$ adsorbed molecule.

\subsection{Hydrogen production}

${ }_{25}$ The hydrogen production experiments were carried out irradiating with UV light slurries containing $1 \mathrm{~g} \mathrm{~L}^{-1}$ of $\mathrm{TiO}_{2}$ powder and $2 \mathrm{mg} \mathrm{L}^{-1}$ of $\mathrm{Pt}$, added as $\mathrm{H}_{2} \mathrm{PtCl}_{6}$. The $\mathrm{pH}$ of the suspension was 
buffered at 3.8 with the addition of a formic acid-sodium formate buffer $0.1 \mathrm{M}$. The formate buffer acts also as hole scavenger. The irradiation experiments were carried out in magnetically stirred, cylindrical quartz cells $(3.5 \mathrm{~cm}$ inner diameter, $2 \mathrm{~cm}$ height), containing $5 \mathrm{~mL}$ of slurry. Before irradiation the cell containing the slurry was carefully purged with nitrogen to remove oxygen from the reaction environment. Hydrogen evolution was followed withdrawing periodically $2.5 \mathrm{ml}$ of gas from the irradiation cell and replacing it with the same volume of $\mathrm{N}_{2}$. The gas sample was analysed with an Agilent 490 Micro GC gas chromatograph equipped with a Molsieve $5 \AA$ ć column. During the analysis the column was kept at a temperature of $90^{\circ} \mathrm{C}$ and at a pressure of $200 \mathrm{kPa}$, the carrier gas was argon. The total amount of $\mathrm{H}_{2}$ produced as a function of time was calculated from the concentration in the sampled gas, from the volume of gas in the irradiation cell and considering the previous samplings.

To evaluate the effect of the slow photons the irradiations were performed at two different UV wavelengths (365 nm and $254 \mathrm{~nm})$. The radiation source at $365 \mathrm{~nm}$ was a Philips PLS-10 lamp at a distance of $10 \mathrm{~cm}$ from the quartz cell with a flat $\mathrm{Al}$ foil as a reflector. The irradiance on top of the solutions was $78 \mathrm{~W} \mathrm{~m}^{-2}$, measured with a CO.FO.ME.GRA. power meter. Irradiation at $254 \mathrm{~nm}$ was carried out with a $9 \mathrm{~W}$ Philips TUV PL-S lamp at a distance of $10 \mathrm{~cm}$ from the quartz cell, emitting 2.3 $\mathrm{W}$ in UVC. Fig. 1 reports the emission spectra of the two lamps, measured with an Ocean Optics SD2000 CCD.

\subsection{Computational details}

Photonic bands diagrams have been calculated with a freely available software [31].

\section{Results and discussion}

\subsection{Powders characterization}

In the present work five different samples have been studied. Among them two have been prepared starting from PMMA templates. Their AFM, SEM and optical spectra, as well as the photocatalytic 
activity toward phenol oxidation have been investigated in a previous work [21]. Two samples have been obtained from PS templates, and, besides the optical and morphological characterization, on them an extensive photoelectrochemical study has been performed by means of voltammetry, potentiometry and electrochemical impedance spectroscopy [22]; the fifth sample was P25, here used as a reference for the activity of the synthesized samples.

The sample prepared using PMMA disordered structure as a template (macroporous disordered structure, MP-PMMA) is a macroporous powder with disordered pore structure, and as a consequence there is no PBG. Using PMMA ordered structure as a template, the inverse opal was obtained (TIO-PMMA). The inverse opal TIO-PMMA has a pore structure with long range order. During calcination the PMMA template shrinks considerably (up to 50\%). Starting from PMMA with particle diameter about $250 \mathrm{~nm}$, the sample TIO-PMMA has pores with diameter around 125 $\mathrm{nm}$ (pseudo-PBG around $280 \mathrm{~nm}$ in air, 320-330 nm in water). Starting from PMMA with particle diameter around 420-450 nm, the sample MP-PMMA has pores with a mean diameter around 220 $\mathrm{nm}[21]$.

The TIO-PS sample, prepared from the PS opal powder, has an ordered arrangement of the pores, each pore has a diameter of $250 \mathrm{~nm}$ and it is separated from its closest neighbours by $80 \mathrm{~nm}$ thick $\mathrm{TiO}_{2}$ walls. The corresponding opal template was composed of PS spheres with diameter of 360 $\mathrm{nm}$, indicating a limited shrinkage with respect to PMMA. In this case the pseudo-PBG is located at $500 \mathrm{~nm}$, but there are photonic bands characterised by low group velocity also at 330-380 nm [22]. The sample MP-PS has a very similar pore size distribution, but its structure lacks in long range order, and, as in the case of MP-PMMA, there is no PBG and no way to exploit the slow photon effect [22].

The pore size distributions and the specific surface areas (SSA) of the samples synthesized are summarized in Table 1. The powders obtained from PS templates have higher specific surface area with respect to PMMA templates. In addition the data of Table 1 suggest that the surface area increases with the pore size at the $3 / 2$ power, opposite to the expected inverse dependence. As 
mentioned before PMMA templates shrink during calcination, and this process can cause the occlusion of part of the macropores, resulting in a reduced SSA. In the case of smaller macropores the channels connecting the macropores network are also smaller and easier to occlude.

${ }_{4}$ X-ray powder diffractograms reported in Fig. 2 show that anatase is the dominant $\mathrm{TiO}_{2}$ crystalline phase when PMMA is used as sacrificial template, while rutile is present only as a trace $(<2 \%)$. When PS is used as polymer template, the presence of rutile and brookite, in the sample TIO-PS, becomes significant. MP-PS contains about $30 \%$ of rutile, while TIO-PS is composed of $57 \%$ anatase, $36 \%$ brookite and $7 \%$ rutile. These relative amounts are only approximate, because it is not possible to finely homogenize the samples without losing the properties arising from the $3 \mathrm{D}$ structure of the powders. These differences in compositions can be explained in terms of the chemical properties of the polymer templates. PMMA has a certain number of carboxylate groups, and it is known that carboxylate can complex preferentially anatase $\{001\}$ facets, changing the growing rate ratio of $\{001\}$ facets to $\{101\}$ facets [32-35]. The diffractograms reported in Fig. 2 suggest also that the carboxylate groups can favour the nucleation of anatase rather than rutile or brookite, since in the samples obtained using PMMA as template rutile and brookite are almost absent.

\subsection{Hydrogen production}

The initial slurry contains the photocatalyst as a suspended solid, $\mathrm{H}_{2} \mathrm{PtCl}_{6}$ and the formate buffer. In the first step of the irradiation, the photoelectrons produced by UV light reduce $\operatorname{Pt}(\mathrm{IV})$ to $\operatorname{Pt}(0)$, and are responsible for the Pt photodeposition [36]. In this process the formate buffer has the function of hole scavenger. Once the Pt is deposited and the suspension turned to a pale grey, the production of hydrogen started. Fig. 3 reports the cumulative hydrogen produced as a function of the time. The extrapolation of the trends when hydrogen production starts (intercept with the abscissa) shows that at both $254 \mathrm{~nm}$ and $365 \mathrm{~nm}$ the hydrogen evolution begins even before the fifth minute of irradiation. In some cases the hydrogen evolution seems to start at even negative times: this effect is 
due to the non-linearity of hydrogen production in the very first minutes of irradiation, after which it follows a linear trend. The rates are reported in Fig.4, together with the rates normalized by the SSA.

From a general analysis of the plots in Fig. 3 and Fig. 4 it can be seen that at $254 \mathrm{~nm}$ the hydrogen production rates and the SSA normalized rates roughly double with respect to the rates observed at $365 \mathrm{~nm}$. The comparison of the absolute rates at $254 \mathrm{~nm}$ and $365 \mathrm{~nm}$ is challenging because the intensity of the incident light is different, and other factors like the different absorption coefficient of $\mathrm{TiO}_{2}$ at those wavelengths and the different scattering of light [37] are difficult to be estimated. Thus, only are the relative rates at each wavelength significant to assess the role of the material geometrical arrangement.

Considering the $365 \mathrm{~nm}$ irradiation using the TIO-PMMA and MP-PMMA samples (Fig. 4b) it can be seen that the ordered three dimensional structure nearly doubles the surface normalized photocatalytic activity of P25 and macroporous disordered specimen. The same observation can be made for the powders obtained from PS templates, even if, in this case, TIO-PS is only $25 \%$ more active than its macroporous homologue (Fig 4b). In general, both for the rate and the normalized rate the performance is in the order MP $<$ TIO. Since at those photon energies flat photonic bands in the diagram frequency $(\omega)$ vs wavevector $(k)$ are present for both TIO-PMMA and TIO-PS (Fig. 5), slow photons can reasonably be the cause of the observed differences in hydrogen production, since, considering separately PMMA and PS derived samples, minor differences in surface chemistry or crystallinity exist due to the same synthesis conditions. Thus, the major difference among TIOs and their macroporous MP analogues is the $3 \mathrm{D}$ arrangement of the pores that influences the ability to absorb the incident light.

At $254 \mathrm{~nm}$ (Fig. 4a), both for the rate and the normalized rate the performance follows the trend MP $>$ TIO. The surface normalized rate of the sample TIO-PMMA is very similar to that of MPPMMA, and in the case of PS template samples MP-PS is definitely more active than TIO-PS. Considering the photonic band diagram of TIO-PS (Fig. 5) at $254 \mathrm{~nm}$ there are few photonic bands 
characterized by a low group velocity. At those energies $\mathrm{TiO}_{2}$ has a higher absorption coefficient [38], and the lengthening of the effective optical path due to slow photons is not crucial in increasing the absorbance.

4 Comparing now the rates of the samples focusing on the different chemical composition of the templates (Fig. 4) it can be noticed that although the rates are comparable, the surface normalized rates of PS samples are significantly lower with respect to PMMA samples both at $365 \mathrm{~nm}$ and 254 $\mathrm{nm}$, because of the higher SSAs of the PS samples. The polymer template has an influence on the crystalline phases present in the synthesized samples (Fig. 2) and also an effect on the surface properties is very likely. Since photocatalytic properties depend on the $\mathrm{TiO}_{2}$ crystalline phases and on the surface exposed [39], the choice of the polymer template has an influence on the behaviour of the material under irradiation. It has been demonstrated that the activity in hydrogen photoproduction depends on the particle shape and on the facets exposed by the catalyst, and anatase nanoparticles synthesized in the presence of carboxylic acids and exposing $\{001\}$ facets are very active $[40,41]$. The fact that $\mathrm{TiO}_{2}$ structures obtained from PMMA templates are, for the most part, more active than those obtained with PS is in agreement with those results. Moreover, the presence of rutile in the PS samples, characterized by a lower energy of the conduction band [42] with respect to anatase, decreases the energy of the conduction band with respect to samples obtained from PMMA, where almost only anatase is present (Table 1), and decreases the overpotential available for the $\mathrm{H}_{2}$ production, resulting in a lower activity.

We reported a higher reaction rate of photogenerated electrons with oxygen present in solution for the TIO-PS sample with respect to its MP-PS homologue, while the recombination rate of the ${ }_{22}$ photogenerated charge carriers was the same in both TIO-PS and MP-PS [22]. Following this evidence, we expected a faster hydrogen evolution from the TIO-PS sample by irradiation at 254 $\mathrm{nm}$, where the effect of slow photons is negligible. A greater activity of TIOs at $254 \mathrm{~nm}$ would be the evidence of a faster electron transfer rate in TIOs with respect to macroporous analogues. On the contrary, we observed slightly lower activities for the TIOs compared to MP samples (Fig. 4a). 
This is the evidence that the improvement in TIO activity at $365 \mathrm{~nm}$ is entirely due to the slow photon effect (Fig. 4b). This also suggests that the electron transfer to solution via the Pt co-catalyst on TIOs is by no means faster than for MP structures. The production of $\mathrm{H}_{2}$ occurs on $\mathrm{Pt}$ sites with small overpotentials, and the rate determining step can be the electron transfer from the metal to $\mathrm{H}^{+}$ or water [43], or the catalytic desorption of $\mathrm{H}_{2}$ from the Pt surface [44]. This situation is completely different from the dioxygen reduction on $\mathrm{TiO}_{2}$, where the reduction occurs on adsorbed oxygen (surface traps) with high overpotentials [43].

\section{Conclusions}

Irradiation experiments performed at $254 \mathrm{~nm}$ show that TIOs and disordered MP structures obtained from the same polymer template (PMMA or PS) have hydrogen production rate in the order MP > TIO. Upon irradiation at $365 \mathrm{~nm}$ due to the slow light phenomenon the synthesized $\mathrm{TiO}_{2}$ inverse opals have hydrogen production rate (or SSA normalized rate) larger than disordered macroporous structures that did not possess an ordered arrangement of the pores ( $\mathrm{MP}<\mathrm{TIO})$. The increase in activity is due to a better exploitation of the incident light. The rate of the synthesized $\mathrm{TiO}_{2}$ powders is also influenced by the chemical properties of the polymeric template, which determines not only the pore size and the order of the pore structure, but also the $\mathrm{TiO}_{2}$ crystalline phases. Nevertheless, these and other factors such as the kinetics of the charge transfer at the interface, or the different crystalline facets exposed [45], cannot account for the different orders of reactivity found at different irradiation wavelengths, because the better exploitation of light is the cause of this phenomenon, which is observed both for oxidation [20] and, in this work, for reduction reactions. Owing to this, the strategy can be conveniently used in every photocatalytic reaction. 


\section{Acknowledgements}

The authors thank Dr. Giuliana Magnacca for her helpfulness and expertise in nitrogen adsorption experiments. The financial support from project PHOTORECARB - Progetti di Ateneo/CSP 2012 Call 03 - Università di Torino \& Compagnia di S.Paolo - is gratefully acknowledged. 
Table 1: Specific surface area, diameter of the macropores and $\mathrm{TiO}_{2}$ crystalline phases present in the $\mathrm{TiO}_{2}$ powders synthesized (A: anatase, B: brookite, $\mathrm{R}$ : rutile)

\begin{tabular}{l|c|c|l}
\hline Sample & SSA $\left(\mathbf{m}^{2} \mathbf{g}^{-1}\right)$ & $\begin{array}{l}\text { Macropore } \\
\text { size }(\mathbf{n m})\end{array}$ & Crystalline phases \\
\hline TIO-PMMA & 18 & 125 & Anatase, Rutile $<1 \%$ \\
MP-PMMA & 28 & $200-220$ & Anatase, Rutile $\approx 2 \%$ \\
TIO-PS & 74 & 330 & $A \approx 57 \%, B \approx 36 \%, R \approx 7 \%$ \\
MP-PS & 69 & $300-330$ & $A \approx 70 \%, R \approx 30 \%$ \\
P25 & $45^{[46]}$ & - & $A \approx 80 \%, R \approx 20 \%[47]$ \\
\hline
\end{tabular}




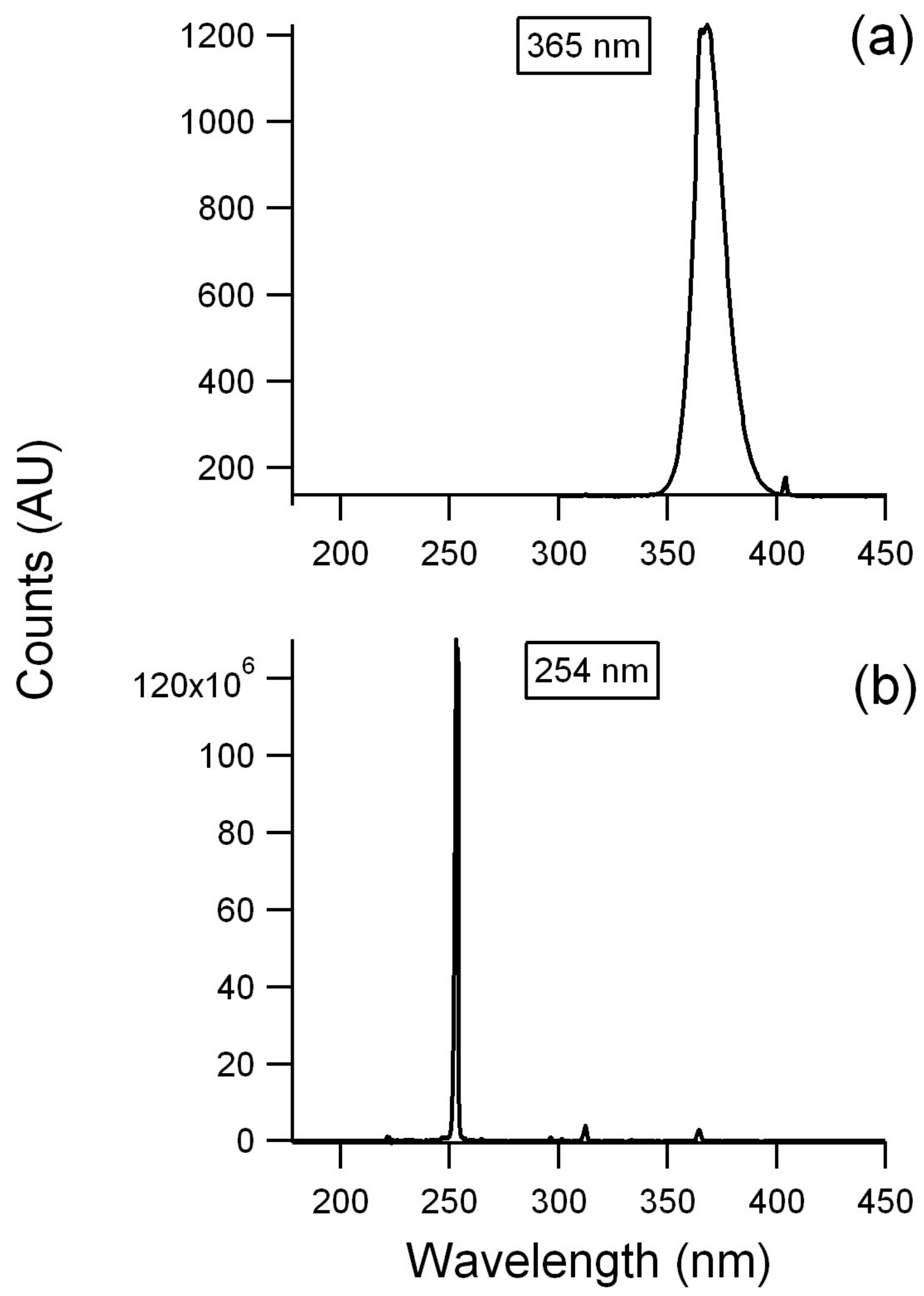

Fig. 1 


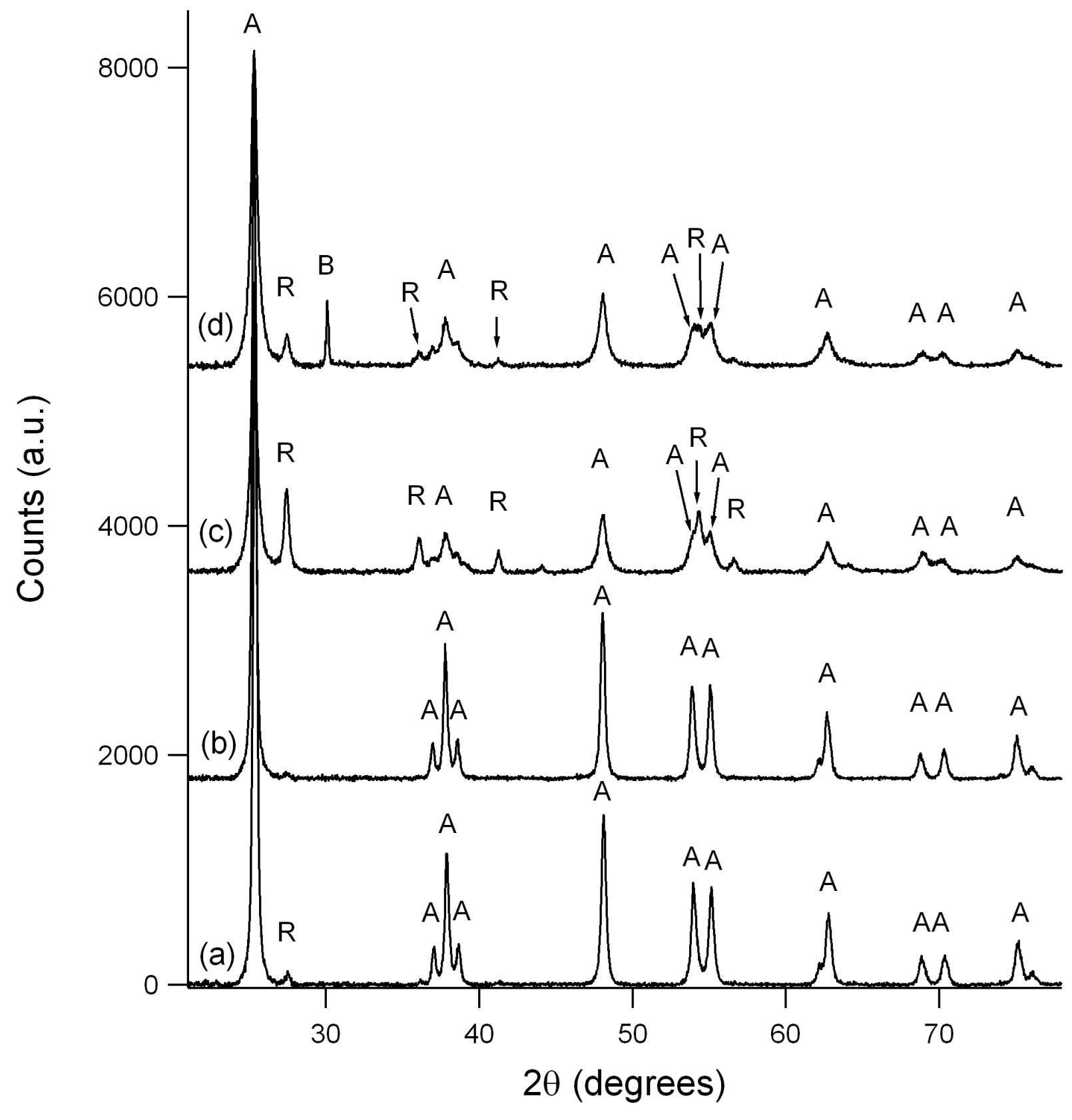

Fig. 2 

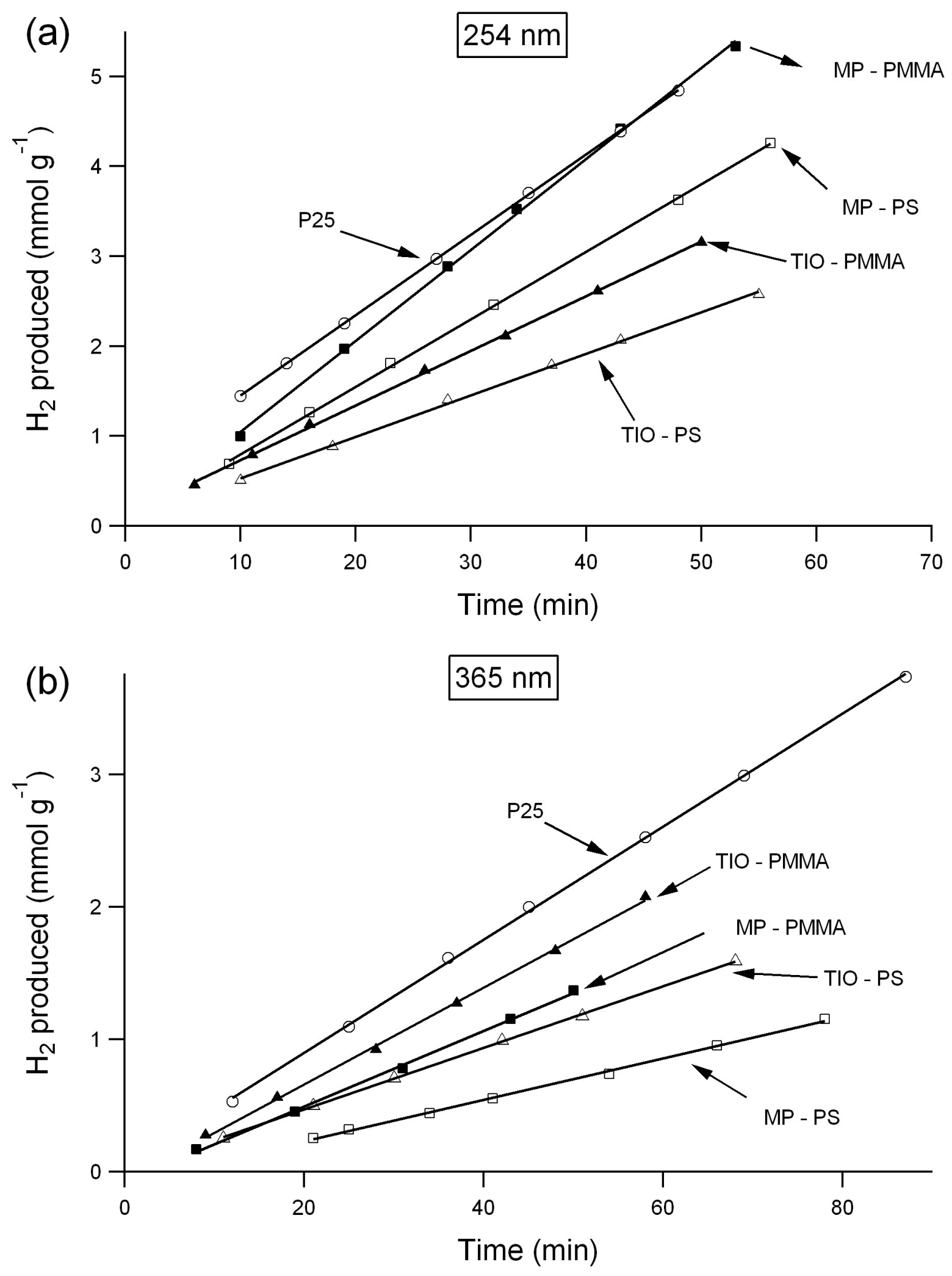

Fig. 3 

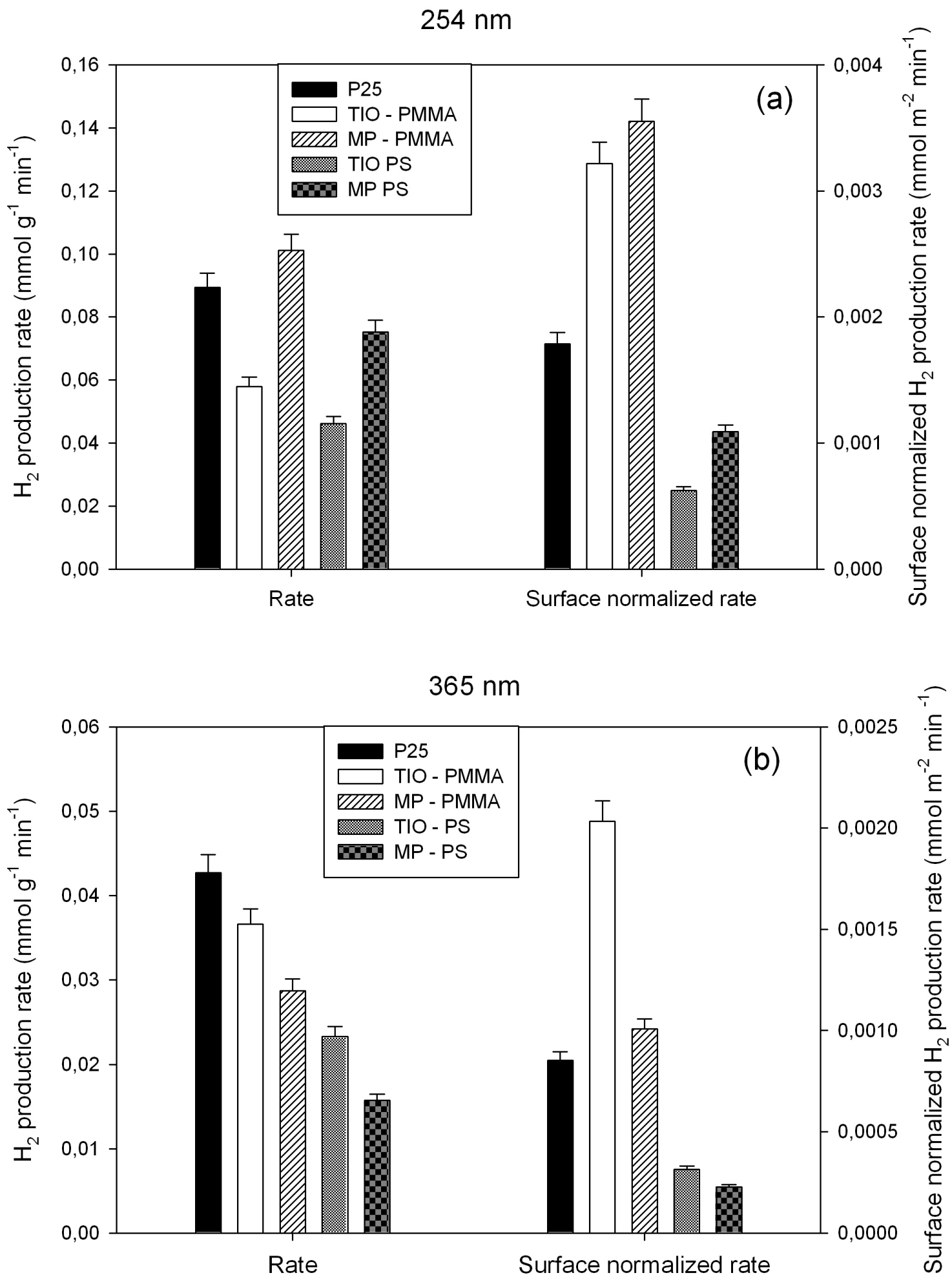

Fig. 4 


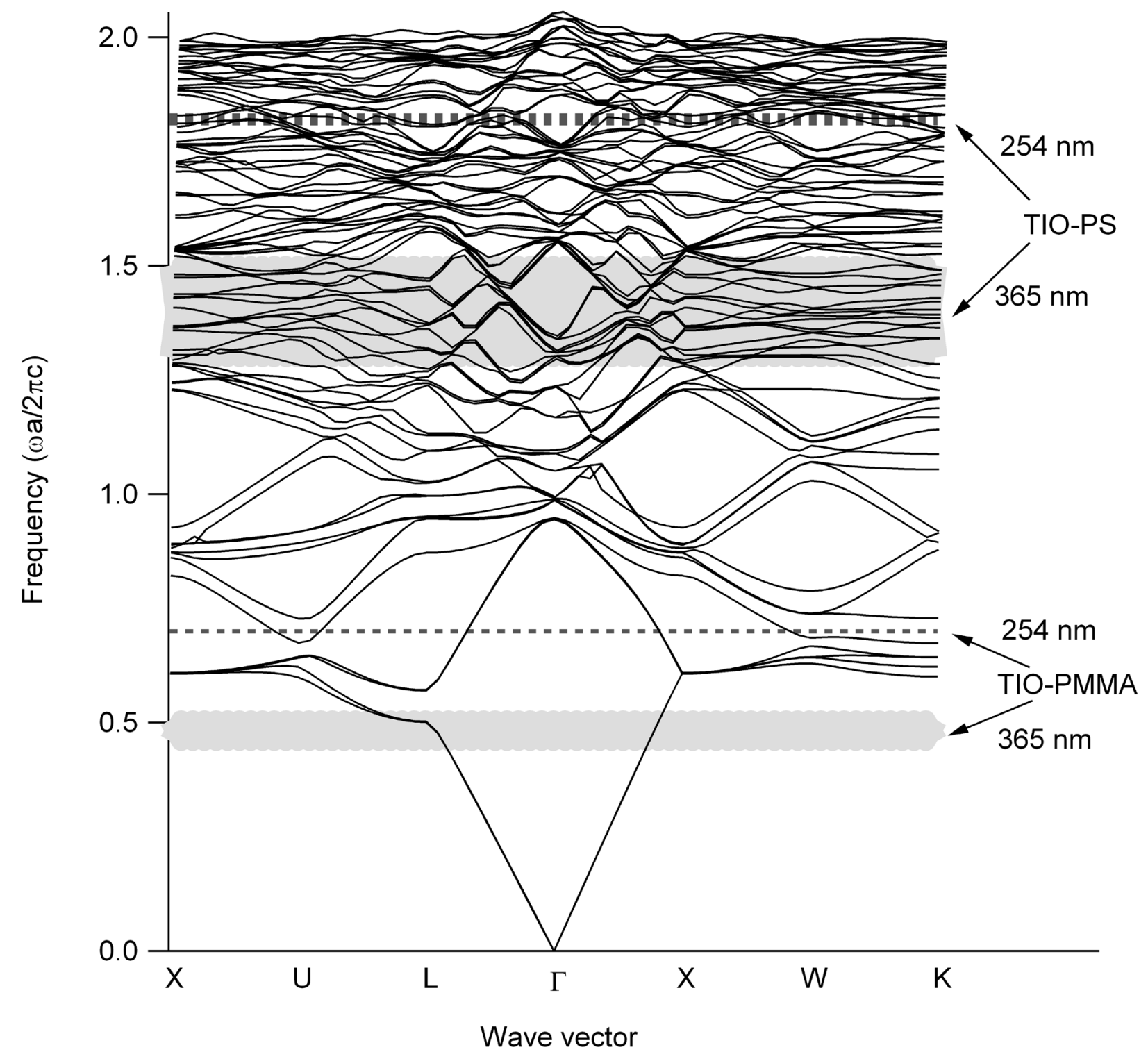

Fig. 5 


\section{Table caption}

Table 1: Specific surface area, diameter of the macropores and $\mathrm{TiO}_{2}$ crystalline phases present in the $\mathrm{TiO}_{2}$ powders synthesized (A: anatase, $\mathrm{B}$ : brookite, $\mathrm{R}$ : rutile) 


\section{Figures captions}

Fig. 1 Emission spectra of a Philips TUV PL-S lamp (a) and of a Philips PLS-10 lamp (b).

Fig. 2 XRD patterns of (a) MP-PMMA, (b) TIO-PMMA, (c) MP-PS and (d) TIO-PS. The letter A denotes anatase, $\mathrm{B}$ brookite and $\mathrm{R}$ rutile.

Fig. 3 Hydrogen produced as a function of the irradiation time for suspensions containing $1 \mathrm{~g} \mathrm{~L}^{-1}$ of different $\mathrm{TiO}_{2}$ powders and $2 \mathrm{mg} \mathrm{L}^{-1}$ of $\mathrm{Pt}$ in the presence of formate buffer $0.1 \mathrm{M}$ at $\mathrm{pH} 3.8$. The radiation source had an emission maximum at $254 \mathrm{~nm}$ (a) and at $365 \mathrm{~nm}$ (b).

Fig. 4 Hydrogen production rates and surface normalized rates for powder samples irradiated at 254 $\mathrm{nm}$ (a) and at $365 \mathrm{~nm}$ (b). All samples were suspensions containing $1 \mathrm{~g} \mathrm{~L}^{-1}$ of different $\mathrm{TiO}_{2}$ and 2 $\mathrm{mg} \mathrm{L}^{-1}$ of $\mathrm{Pt}$ in the presence of formate buffer $0.1 \mathrm{M}$ at $\mathrm{pH} 3.8$.

Fig. 5 Calculated photonic band diagram for TIO powders in water with data of Table 1. The frequencies used during irradiation experiments are highlighted. For $\mathrm{TiO}_{2} \varepsilon_{1}=5.5$; for water $\varepsilon_{1}=$ 1.7. 
Research highlights

1- $\mathrm{TiO}_{2}$ inverse opals and macroporous $\mathrm{TiO}_{2}$ were used in $\mathrm{H}_{2}$ production experiments

2- Inverse opals show higher rates due to slow photons

3- Polymer template influences the crystallinity and the performance of $\mathrm{TiO}_{2}$ samples

4- No evidence for faster electron transfer in TIOs during $\mathrm{H}_{2}$ photoproduction

5- Inverse opal are effective both on oxidation and reduction photocatalytic reactions 


\section{References}

[1] E. Yablonovitch, Photonic crystals: Semiconductors of light, Sci. Am., 285 (2001) 46-50.

[2] J.D. Joannopoulos, S.G. Johnson, J.N. Winn, R.D. Meade, Photonic Crystals

Molding the Flow of Light, second ed., Princeton University Press, Princeton, 2008.

[3] M. Ishii, M. Harada, A. Tsukigase, H. Nakamura, Three-dimensional structure analysis of opaline photonic crystals by angle-resolved reflection spectroscopy, J. Opt. A-Pure Appl. Op., 9 (2007) S372-S376.

[4] A. Mihi, M.E. Calvo, J.A. Anta, H. Miguez, Spectral response of opal-based dye-sensitized solar cells, J. Phys. Chem. C, 112 (2008) 13-17.

[5] S. Nishimura, N. Abrams, B.A. Lewis, L.I. Halaoui, T.E. Mallouk, K.D. Benkstein, J. van de Lagemaat, A.J. Frank, Standing wave enhancement of red absorbance and photocurrent in dye-sensitized titanium dioxide photoelectrodes coupled to photonic crystals, J. Am. Chem. Soc., 125 (2003) 6306-6310.

[6] P.G. O'Brien, N.P. Kherani, A. Chutinan, G.A. Ozin, S. John, S. Zukotynski, Silicon photovoltaics using conducting photonic crystal back-reflectors, Adv. Mater., 20 (2008) 1577-1582.

[7] X. Letartre, C. Seassal, C. Grillet, P. Rojo-Romeo, P. Viktorovitch, M.L. d'Yerville, D. Cassagne, C. Jouanin, Group velocity and propagation losses measurement in a single-line photonic-crystal waveguide on $\mathrm{InP}$ membranes, Appl. Phys. Lett., 79 (2001) 2312-2314.

[8] I.D.W. Samuel, G.A. Turnbull, Organic Semiconductor Lasers, Chem. Rev., 107 (2007) 1272-1295.

[9] A. Mekis, M. Meier, A. Dodabalapur, R.E. Slusher, J.D. Joannopoulos, Lasing mechanism in two-dimensional photonic crystal lasers, Appl. Phys. A: Mater. Sci. Process., 69 (1999) 111-114.

[10] M. Florescu, H. Lee, I. Puscasu, M. Pralle, L. Florescu, D.Z. Ting, J.P. Dowling, Improving solar cell efficiency using photonic band-gap materials, Sol. Energy Mater. Sol. Cells, 91 (2007) 1599-1610.

[11] T. Baba, Slow light in photonic crystals, Nat. Photonics, 2 (2008) 465-473.

[12] Y. Zhao, H.-W. Zhao, X.-Y. Zhang, B. Yuan, S. Zhang, New mechanisms of slow light and their applications, Opt. Laser Technol., 41 (2009) 517-525.

[13] M.-C. Tsai, J.-Y. Lee, P.-C. Chen, Y.-W. Chang, Y.-C. Chang, M.-H. Yang, H.-T. Chiu, I.N. Lin, R.-K. Lee, C.-Y. Lee, Effects of size and shell thickness of $\mathrm{TiO} 2$ hierarchical hollow spheres on photocatalytic behavior: An experimental and theoretical study, Applied Catalysis B: Environmental, 147 (2014) 499-507.

[14] M.M. Ren, R. Ravikrishna, K.T. Valsaraj, Photocatalytic degradation of gaseous organic species on photonic bandgap titania, Environ. Sci. Technol., 40 (2006) 7029-7033.

[15] M. Srinivasan, T. White, Degradation of methylene blue by three-dimensionally ordered macroporous titania, Environ. Sci. Technol., 41 (2007) 4405-4409.

[16] Q. Li, J.K. Shang, Inverse opal structure of nitrogen-doped titanium oxide with enhanced visible-light photocatalytic activity, J. Am. Ceram. Soc., 91 (2008) 660-663.

[17] W.T. Dong, H.J. Bongard, F. Marlow, New type of inverse opals: Titania with skeleton structure, Chem. Mater., 15 (2003) 568-574.

[18] F. Sordello, V. Maurino, C. Minero, Improved Photochemistry of $\mathrm{TiO}_{2}$ Inverse Opals and Some Examples, in: D.S. Saha (Ed.) Molecular Photochemistry - Various Aspects, InTech 2012, pp. 63-86.

[19] J.I.L. Chen, E. Loso, N. Ebrahim, G.A. Ozin, Synergy of slow photon and chemically amplified photochemistry in platinum nanocluster-loaded inverse titania opals, J. Am. Chem. Soc., 130 (2008) 5420-5421.

[20] J.I.L. Chen, G. vonFreymann, S.Y. Choi, V. Kitaev, G.A. Ozin, Amplified Photochemistry with Slow Photons, Adv. Mater., 18 (2006) 1915-1919.

[21] F. Sordello, C. Duca, V. Maurino, C. Minero, Photocatalytic metamaterials: $\mathrm{TiO}_{2}$ inverse opals, Chem. Commun., 47 (2011) 6147-6149.

[22] F. Sordello, V. Maurino, C. Minero, Photoelectrochemical study of $\mathrm{TiO}_{2}$ inverse opals, J. Mater. Chem., 21 (2011) 19144 - 19152.

[23] M. Wu, J. Liu, J. Jin, C. Wang, S. Huang, Z. Deng, Y. Li, B.-L. Su, Probing significant light absorption enhancement of titania inverse opal films for highly exalted photocatalytic degradation of dye pollutants, Applied Catalysis B: Environmental, 150-151 (2014) 411-420.

[24] S. Sun, W. Wang, L. Zhang, J. Xu, $\mathrm{Bi}_{2} \mathrm{WO}_{6} / \mathrm{SiO}_{2}$ photonic crystal film with high photocatalytic activity under visible light irradiation, Applied Catalysis B: Environmental, 125 (2012) 144-148.

[25] D. Qi, L. Lu, Z. Xi, L. Wang, J. Zhang, Enhanced photocatalytic performance of TiO2 based on synergistic effect of Ti3+ self-doping and slow light effect, Applied Catalysis B: Environmental, 160-161 (2014) 621-628.

[26] S. Chai, G. Zhao, Y. Wang, Y.-n. Zhang, Y. Wang, Y. Jin, X. Huang, Fabrication and enhanced electrocatalytic activity of 3D highly ordered macroporous $\mathrm{PbO}_{2}$ electrode for recalcitrant pollutant incineration, Applied Catalysis B: Environmental, 147 (2014) 275-286.

[27] G.I.N. Waterhouse, M.R. Waterland, Opal and inverse opal photonic crystals: Fabrication and characterization, Polyhedron, 26 (2007) 356-368.

[28] J.W. Goodwin, J. Hearn, C.C. Ho, R.H. Ottewill, Studies on the preparation and characterisation of monodisperse polystyrene laticee, Colloid Polym. Sci., 252 (1974) 464-471. 
[29] H. Zhang, J.F. Banfield, Understanding Polymorphic Phase Transformation Behavior during Growth of Nanocrystalline Aggregates: Insights from TiO2, J. Phys. Chem. B, 104 (2000) 3481-3487.

[30] S. Brunauer, P.H. Emmett, E. Teller, Adsorption of Gases in Multimolecular Layers, J. Am. Chem. Soc., 60 (1938) 309-319.

[31] S.G. Johnson, J.D. Joannopoulos, Block-iterative frequency-domain methods for Maxwell's equations in a planewave basis, Opt. Express, 8 (2001) 173-190.

[32] C.-T. Dinh, T.-D. Nguyen, F. Kleitz, T.-O. Do, Shape-Controlled Synthesis of Highly Crystalline Titania Nanocrystals, ACS Nano, 3 (2009) 3737-3743.

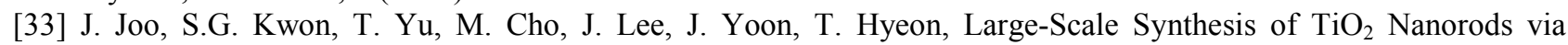
Nonhydrolytic Sol-Gel Ester Elimination Reaction and Their Application to Photocatalytic Inactivation of E. coli, J. Phys. Chem. B, 109 (2005) 15297-15302.

[34] Y.-w. Jun, M.F. Casula, J.-H. Sim, S.Y. Kim, J. Cheon, A.P. Alivisatos, Surfactant-Assisted Elimination of a High Energy Facet as a Means of Controlling the Shapes of $\mathrm{TiO}_{2}$ Nanocrystals, J. Am. Chem. Soc., 125 (2003) 15981-15985.

[35] X.-L. Li, Q. Peng, J.-X. Yi, X. Wang, Y. Li, Near Monodisperse $\mathrm{TiO}_{2}$ Nanoparticles and Nanorods, Chem. Eur. J., 12 (2006) 2383-2391.

[36] B. Kraeutler, A.J. Bard, Heterogeneous photocatalytic preparation of supported catalysts. Photodeposition of platinum on titanium dioxide powder and other substrates, J. Am. Chem. Soc., 100 (1978) 4317-4318.

[37] C. Minero, D. Vione, A quantitative evalution of the photocatalytic performance of $\mathrm{TiO}_{2}$ slurries, Applied Catalysis B: Environmental, 67 (2006) 257-269.

[38] G.E. Jellison, L.A. Boatner, J.D. Budai, B.S. Jeong, D.P. Norton, Spectroscopic ellipsometry of thin film and bulk anatase (TiO2), J. Appl. Phys., 93 (2003) 9537-9541.

[39] W.Q. Fang, X.-Q. Gong, H.G. Yang, On the Unusual Properties of Anatase $\mathrm{TiO}_{2}$ Exposed by Highly Reactive Facets, J. Phys. Chem. Lett., 2 (2011) 725-734.

[40] H.J. Yun, H. Lee, J.B. Joo, N.D. Kim, J. Yi, Effect of $\mathrm{TiO}_{2}$ Nanoparticle Shape on Hydrogen Evolution via Water Splitting, J. Nanosci. Nanotechnol., 11 (2011) 1688-1691.

[41] T. Kimijima, T. Sasaki, M. Nakaya, K. Kanie, A. Muramatsu, Photocatalytic Activity of Ni-loaded TiO 2 Nanoparticles Precisely Controlled in Size and Shape, Chem. Lett., 39 (2010) 1080-1081.

[42] L. Kavan, M. Grätzel, S.E. Gilbert, C. Klemenz, H.J. Scheel, Electrochemical and Photoelectrochemical Investigation of Single-Crystal Anatase, J. Am. Chem. Soc., 118 (1996) 6716-6723.

[43] Z. Kasarevic-Popovic, D. Behar, J. Rabani, Role of Excess Electrons in TiO2 Nanoparticles Coated with Pt in Reduction Reactions Studied in Radiolysis of Aqueous Solutions, J. Phys. Chem. B, 108 (2004) 20291-20295.

[44] R. Baba, S. Nakabayashi, A. Fujishima, K. Honda, Investigation of the mechanism of hydrogen evolution during photocatalytic water decomposition on metal-loaded semiconductor powders, J. Phys. Chem., 89 (1985) 1902-1905.

[45] J. Yu, J. Low, W. Xiao, P. Zhou, M. Jaroniec, Enhanced Photocatalytic CO2-Reduction Activity of Anatase TiO 2 by Coexposed $\{001\}$ and $\{101\}$ Facets, J. Am. Chem. Soc., 136 (2014) 8839-8842.

[46] J. Yu, J. Fan, B. Cheng, Dye-sensitized solar cells based on anatase $\mathrm{TiO}_{2}$ hollow spheres/carbon nanotube composite films, J. Power Sources, 196 (2011) 7891-7898.

[47] C. Karunakaran, G. Abiramasundari, P. Gomathisankar, G. Manikandan, V. Anandi, Preparation and characterization of $\mathrm{ZnO}-\mathrm{TiO} 2$ nanocomposite for photocatalytic disinfection of bacteria and detoxification of cyanide under visible light, Mater. Res. Bull., 46 (2011) 1586-1592. 